Asia Pacific Journal of Advanced Business and Social Studies

ISBN (eBook): 9780994365675 | ISSN : 2205-6033

Year: 2018 , Volume: 4, 155ue: 2

\title{
DOESFOREIGN DIRECT INVESTMENT AFFECT INCOME INEQUALITY? A THRESHOLD REGRESSION ANALYSIS IN VIETNAM
}

\author{
Tho Quynh Nguyen \\ Banking Academy of Vietnam, Vietnam \\ Corresponding Email: thonq@hvnh.edu.vn
}

\begin{abstract}
The benefits of FDI consist of being as an important source of capital, contributing to employment, transferring technology, increasing competition and generating spillover effects to domestic companies. However, the literature on equality argued that while FDI may bring many benefits to the host economy, it does not mean that everyone in the country could benefit in the same way. According to Figini \& Gorg (2011); Herzer \& Nunnenkamp (2011); Kyriacou \& RocaSagales (2012), the growth of host economies and FDI inflows have been widening the income gap between rich and poor segments of population, between high and low skilled labours, which leads to the increase in income inequality. This paper aims to explore the relationship between FDI and income inequality in Vietnam using Panel Threshold Regression for a recent period (2006-2015), and examine the existence of FDI threshold(s) at which the impact of FDI on income inequality is minimal. By using a panel data of cities and provinces in Vietnam in the period of $2006-2015$, this paper examines the relationship between regional income inequality and FDI growth using fixed effect threshold model developed by Hansen (1999). The findings indicate that FDI directly has a negative effect on income equality. Furthermore, the results show that FDI can influence on inequality indirectly through its impact on GDP. We found strong evidence that there are two threshold levels of FDI in the regression relationship. They are $4.38 \%$ and $11.96 \%$ of GDP with asymptotic $95 \%$ confidence interval. These thresholds divide the observations into three regimes, in which the relationship between GDP and inequality has an inverted U-shape. This finding is consistent with the previous studies on other countries such as Figini \& Gorg (2011) and Kyriacou \& Roca-Sagales (2012). It implies the tradeoffs of the country when trying to attract FDI. The fact in Vietnam shows that the competition among regional governments for the inward FDI generally deepens the gap between the rich and poor resource regions in the country. In the context that Vietnam has been putting so much efforts to attract FDI, this is a warning of an increase in region income inequality in the near future.
\end{abstract}

Keywords: Economic Growth, FDI, Income Inequality, Threshold Effect, Panel Threshold Regression (PTR), Vietnam.

\section{Introduction}

Foreign direct investment (FDI) is often found as an effective channel to boost economic growth in the host country. The benefits of FDI consist of being as an important source of capital, contributing to employment, transferring technology, increasing competition and generating spillover effects to domestic companies. However, the literature on equality argued that while FDI may bring many benefits to the host economy, it does not mean that everyone in the country could benefit in the same way. According to Figini \& Gorg (2011); Herzer \& Nunnenkamp (2011);Kyriacou \& Roca-Sagales (2012), the growth of host economies and FDI 
inflows have been widening the income gap between rich and poor segments of population, between high and low skilled labours, which leads to the increase in income inequality.

In Vietnam, FDI has been playing a crucial role in the country's development. Starting with no foreign investment in 1986, by the end of 2015, Vietnam has received US\$281 billion of FDI for more than 20.000 projects. Over the past 10 years, the annual FDI growth rate of $27.31 \%$ has significantly contributed to the rapid economic growth of Vietnam (GSO, 2016). The income of local labors has been improved. According to World Bank (2014) the income inequality has increased modestly. In the period 1993 - 2012, the average income of the bottom 40 percent of population in Vietnam grew 9\% per year which is "the very highest of growth in the world of the incomes of the bottom 40 percent" (World Bank, 2014). However, World Bank (2014) still raised the concerns about inequality in Vietnam that the income gap between the super-rich and most Vietnamese has been widening. In the Taking Stock Report July 2014 (World Bank, 2014), the comparison between 2003 and 2013 shows that number of super-rich in Vietnam was nearly triple after 10 years (110 super-rich in 2013 compared to only 34 super-rich in 2003). While Vietnam has more and more super-rich, number of the poor has been also increased dramatically. According to new standard of multidimensional poverty, the proportion of poor households in Vietnam in 2015 is around 14\%, unchanged from 2010 (Vietnam Ministry of Labour - invalids and social affairs, 2016).

This paper aims to explore the relationship between FDI and income inequality in Vietnam using Panel Threshold Regression for a recent period (2006-2015), and examine the existence of FDI threshold(s) at which the impact of FDI on income inequality is minimal.

\section{Theoretical Background and Related Empirical Literature}

The literature underlying the relationship between FDI and income inequality are unsettled and can be classified into three camps. The first group of studies supports the hypothesis that FDI is associated with greater income inequality. The uneven distribution of FDI might results in the increasing regional inequality in a country (Wei et al, 2009). According to Taylor and Driffield (2005), the operations of multinational enterprises often require more skill intensive than the domestic firms. In addition, the finding of Te Velde (2001) showed that multinational activity was significantly correlated with skill upgrading. Therefore, FDI benefits skilled workers rather than unskilled workers in poorer host countries (Hanson, 2003; Goldin and Katz, 2008; Lipsey and Sjoholm, 2004).

On the other hand, the empirical evidences from Herzer \& Nunnenkamp (2011); Chintrakarnet al. (2011) lead to the opposite conclusion that FDI may reduce inequality. Using the dataset of ten European countries from 1980 - 2000, Herzer \& Nunnenkamp (2011) found that FDI only increased income inequality in short run, however, in long term an increase in FDI is suggested to reduce income inequality. In a similar vein, Chintrakarn et al. (2011) discovered the same results for the US states for the period 1977 - 2001.To explain this negative relationship, Feenstra and Hanson (1997)argued that the FDI flows from relatively rich source regions to the poorer regions are often accompanied by the skilled labors and technology; thereby it may increase the skill premium not only in the richer region, but also in the poorer ones.

The third group suggests that the effect of FDI on inequality is nonlinear. Aghion and Howitt (1998) pointed out that FDI may benefit local enterprises through spillover effects, then in its turn, these companies' absorptive capacity may results in greater inequality in short run and less inequality in the longer run. Sharing the same viewpoint, Figini and Gorg (1999) analyzed the case of Ireland and found that FDI first increased and then reduced inequality later. In another research, Figini and Gorg (2011) explore this complicated relationship using a panel of more than 100 developing and developed countries. The findings for developing countries suggested the existence of a nonlinear effect, however there is no evidence for developed countries. 
The unsettled argument from different literatures on the relationship between income inequality and FDI can be explained by the differences in development strategy and the contemporary absorptive capacity level of the host country.

In the literature on equality of Vietnam, there are still few studies such as Fritzen (2002), Diep Phan \& Ian Coxhead (2013), Molini \& G. Wan (2008). However, most of them focus on the relationship between inequality and economic growth rather than FDI. In addition, to the best of our knowledge, none of them has examined the existence of a nonlinear relationship between inequality and FDI.

\section{Methodology}

Following Kyriacou \& Roca-Sagales (2012), we use the population weighted coefficient of variation (PW-CV) to measure income inequality. This coefficient can be estimated by the following formula:

$$
\mathrm{PW}-\mathrm{CV}=\frac{1}{y} \sqrt{\sum_{i=1}^{n} p_{i}\left(\bar{y}-y_{i}\right)^{2}}
$$

where $\bar{y}$ is the average country GDP per capita, $\mathrm{y}_{\mathrm{i}}$ and $\mathrm{p}_{\mathrm{i}}$ are the GDP per capital and population share of the region respectively, $\mathrm{n}$ is the number of regions. PW-CV basically presents the inequality among the regions of a country. The coefficient ranges from o (equality) to 1 (maximum inequality).

Inspired by Figini \& Gorg (2011) and Kyriacou \& Roca-Sagales (2012), we focus on examining the impact of FDI on income inequality and attempting to explore whether there is an existence of FDI threshold(s). Accordingly, by using a panel data of 50 cities and provinces of Vietnam for the period $2006-2015$, we start with a basic panel regression:

$$
\mathrm{PWCV}_{i t}=\beta_{o}+\beta_{1} F D I_{i t}+\beta_{2} X+u_{i}+\varepsilon_{i t}
$$

Where $P W C V_{i t}$ is a measure of income inequality in city/province $i$ at time $t . F D I_{i t}$ represent the scale of FDI inflows into city/provincei, at time $t$; $X$ is a vector of control variables assumed to be correlated with inequality (i.e. GDP per capita, expenditure share of regional governments in total public expenditure, region openness, and government quality); $u_{i}$ represent region specific effects and assumed to be unchanged over the time (i.e. regional culture, geographic location); and the observation error $\varepsilon_{i t}$.

However, the basic panel regression model could not show the nature of the relationship between FDI and income inequality changing when the level of FDI increases. So we adopt panel threshold model proposed by Hansen (1999), using Boostrap technique to test the existence of threshold effect which divided the equation into regimes. If there is an existence of at least one threshold value, it implies that the relationship between FDI and income inequality is nonlinear. Following the works of Hansen (1999) and Wang (2015), the specification (2) can be rewritten as follows:

$$
\begin{aligned}
P W C V_{i t} & =\left\{\beta_{1 o}+\beta_{11} F D I_{i t}+\beta_{12} X\right\} d\left[F D I_{i t} \leq \gamma_{1}\right] \\
& +\left\{\beta_{2 o}+\beta_{21} F D I_{i t}+\beta_{22} X\right\} d\left[\gamma_{1}<F D I_{i t} \leq \gamma_{2}\right] \\
& +\left\{\beta_{3 o}+\beta_{31} F D I_{i t}+\beta_{32} X\right\} d\left[F D I_{i t}>\gamma_{2}\right]+u_{i}+\varepsilon_{i t}
\end{aligned}
$$

where $\gamma_{1}, \gamma_{2}$ are the threshold parameters that split the sample into three sub-samples (assuming the model is double-threshold model); $\mathrm{d}($.) is the indicator function which is equal to 1 or 0 , depending on the condition term; the regimes are distinguished by different regression slopes $\alpha$.

Least squares are suggested to determine the thresholds, which are the values that minimize the residual sum of squared: 


$$
\hat{\gamma}=\underset{\gamma \in(\gamma, \bar{\gamma})}{\arg \min } S_{1}(\gamma)
$$

The "no-reject region" method with a likelihood ratio (LR) statistic is used to construct the confidence interval because of the nuisance parameter problem (Hansen, 1999). To examine the existence of a threshold effect, the $\mathrm{F}$ statistic in the likelihood ratio test under $\mathrm{H}_{\mathrm{o}}$ of no threshold effect $\left(\beta_{1}=\beta_{2}\right)$ is constructed as follows:

$$
F_{1}=\frac{S_{0}-S_{1}}{\widehat{\sigma}^{2}}
$$

Furthermore, to examine the significance of threshold effect in the model with the given thresholds, LR statistics and bootstrap approach are applied.

\section{Results and Discussions}

\subsection{Data and Variables}

It would be ideal for data analysis to employ the full data set of 63 cities and provinces in Vietnam, however, due to data gaps, data of only 50 cities and provinces are available. Therefore, the paper uses the panel data of 50 cities and provinces in Vietnam from 2006to 2015 to analyze the relationship between FDI and inequality.

We first control GDP per capital since it naturally influences on the increase of income inequality (Kyriacou\& Roca-Sagales, 2012). However, several empirical evidences showed that inequality may increase at low level of income, but then reduced at higher income (Williamson, 1965; Lessmann, 2009). Our second control variable is fiscal decentralization, measured as expenditure share of regional governments as a percentage of GDP. Empirical studies showed ambiguous findings that fiscal decentralization may either widen the income gap (Prud'homme, 1995; Oates, 1999),or narrow it (McKinnon, 1997; Qian and Weingast, 1997). Region openness is another control variable, measured by the sum of exports and imports as a share of regional GDP. Giannetti (2002) and Petrakos et al (2005) show that openness is associated with the increase in regional inequality. Also, we control for government quality which refers to the level of regional governance. For our purposes here, the ideal proxy for government quality is the average of six governance indicators from World Governance Indicator (Kaufmann et al, 2010). However, in the absence of such measure, we use Provincial Competitiveness Index (PCI) instead. PCI index is constructed by Vietnam Chamber of Commerce and Industry to assess the economic governance quality of provincial authorities. ${ }^{1}$

Table 1: Variables and sources

\begin{tabular}{lll}
\hline Variable & \multicolumn{1}{c}{ Definition } & Source \\
\hline PWCV & $\begin{array}{l}\text { Income inequality measured by the population weighted } \\
\text { standard deviation of regional GDP per capita within a country } \\
\text { divided by the country's GDP per capita }\end{array}$ & GSO (2016) \\
fdi & The net FDI inflow into a region as a share of GDP (\%) & GSO (2016) \\
gdp & Regional GDP per capita & GSO (2016) \\
gov_exp & Total expenditure of regional government as a share of GDP (\%) & GSO (2016) \\
open & Sum of exports and imports as share of regional GDP (\%) & GSO (2016) \\
pci & Provincial Competitiveness Index & VCCI \\
\hline
\end{tabular}

${ }^{1}$ The test for variance inflation factor (VIF) showed no multicollinearity problem with the data set. 


\subsection{Empirical Result}

We first test for the existence of threshold in the model. To do so, we fit the single-threshold model, with the null hypothesis of no threshold effect $\left(\mathrm{H}_{0}: \beta_{11}=\beta_{21}=\beta_{31}\right)$, and the alternative $\mathrm{H}_{1}$ : $\beta_{11} \neq \beta_{21} \neq \beta_{31}$ (threshold effect does exist). Using 300 bootstrap replications to test for a single threshold effect, the existence of threshold is highly significant with a bootstrap p-value of 0.0167. This implies the relationship between income inequality (PWCV) and FDI is non-linear, and there is an existence of at least one threshold.

Table 2: Single threshold model

\begin{tabular}{|c|c|c|c|c|c|c|c|}
\hline model & Threshold & Lower & & Upper & & & \\
\hline Th-1 & 0.1196 & 0.1140 & & 0.1221 & & & \\
\hline \multicolumn{8}{|c|}{ Threshold effect test (bootstrap $=300$ ): } \\
\hline Threshold & RSS & MSE & Fstat & Prob & Crit10 & Crit5 & Critl \\
\hline Single & 0.1192 & 0.0002 & 36.66 & 0.0167 & 18.1435 & 21.5135 & 41.5911 \\
\hline
\end{tabular}

Source: Author's computation in STATA 14

Furthermore, we determine the number of thresholds by sequentially fitting the model with one, two, and three thresholds. The same bootstrap number is used for each of the three bootstrap tests. $\mathrm{F}_{1}$ and $\mathrm{F}_{2}$ statistics in the test for a single and double threshold are highly significant with a bootstrap p-value of 0.0067 and 0.0733 respectively, while the bootstrap p-value of $\mathrm{F}_{3}$ statistic in the test for a triple threshold is not significant (0.62). These imply the existence of two thresholds in the model.

Table 3: Results of threshold effects in different threshold models

\begin{tabular}{r|ccc}
\multicolumn{2}{c}{ Threshold estimator $($ level $=95)$} & \\
\hline model & Threshold & Lower & Upper \\
\hline Th-1 & 0.1196 & 0.1140 & 0.1221 \\
Th-21 & 0.1196 & 0.1170 & 0.1221 \\
Th-22 & 0.0438 & 0.0375 & 0.0438 \\
Th-3 & 0.0881 & 0.0764 & 0.0882 \\
\hline
\end{tabular}

Threshold effect test (bootstrap $=300$
\begin{tabular}{c|ccccccc}
\hline Threshold & RSS & MSE & Fstat & Prob & Crit10 & Crit5 & Crit1 \\
\hline Single & 0.1192 & 0.0002 & 36.66 & 0.0067 & 20.5682 & 24.2803 & 32.6876 \\
Double & 0.1139 & 0.0002 & 22.97 & 0.0733 & 18.0301 & 27.8822 & 38.9638 \\
Triple & 0.1121 & 0.0002 & 7.66 & 0.6200 & 18.9920 & 23.6019 & 42.0062 \\
\hline
\end{tabular}

Source: Author's computation in STATA 14

In order to determine the value of thresholds, we re-estimated the double-threshold model, and found the two thresholds of $11.96 \%$ and $4.38 \%$ respectively. 
Table 4:Double threshold model estimation

Threshold estimator (level = 95):

\begin{tabular}{r|ccc}
\hline model & Threshold & Lower & Upper \\
\hline Th-1 & 0.1196 & 0.1140 & 0.1221 \\
Th-21 & 0.1196 & 0.1170 & 0.1221 \\
Th-22 & 0.0438 & 0.0375 & 0.0438 \\
\hline
\end{tabular}

Threshold effect test (bootstrap $=300$ 300):

\begin{tabular}{c|ccccccc}
\hline Threshold & RSS & MSE & Fstat & Prob & Crit10 & Crit5 & Crit1 \\
\hline Single & 0.1192 & 0.0002 & 36.66 & 0.0100 & 18.2367 & 22.8128 & 30.7137 \\
Double & 0.1139 & 0.0002 & 22.97 & 0.0633 & 19.5430 & 25.1476 & 37.9155 \\
\hline
\end{tabular}

Source: Author's computation in STATA 14

Table 5: Regression Estimates: Double Threshold Model

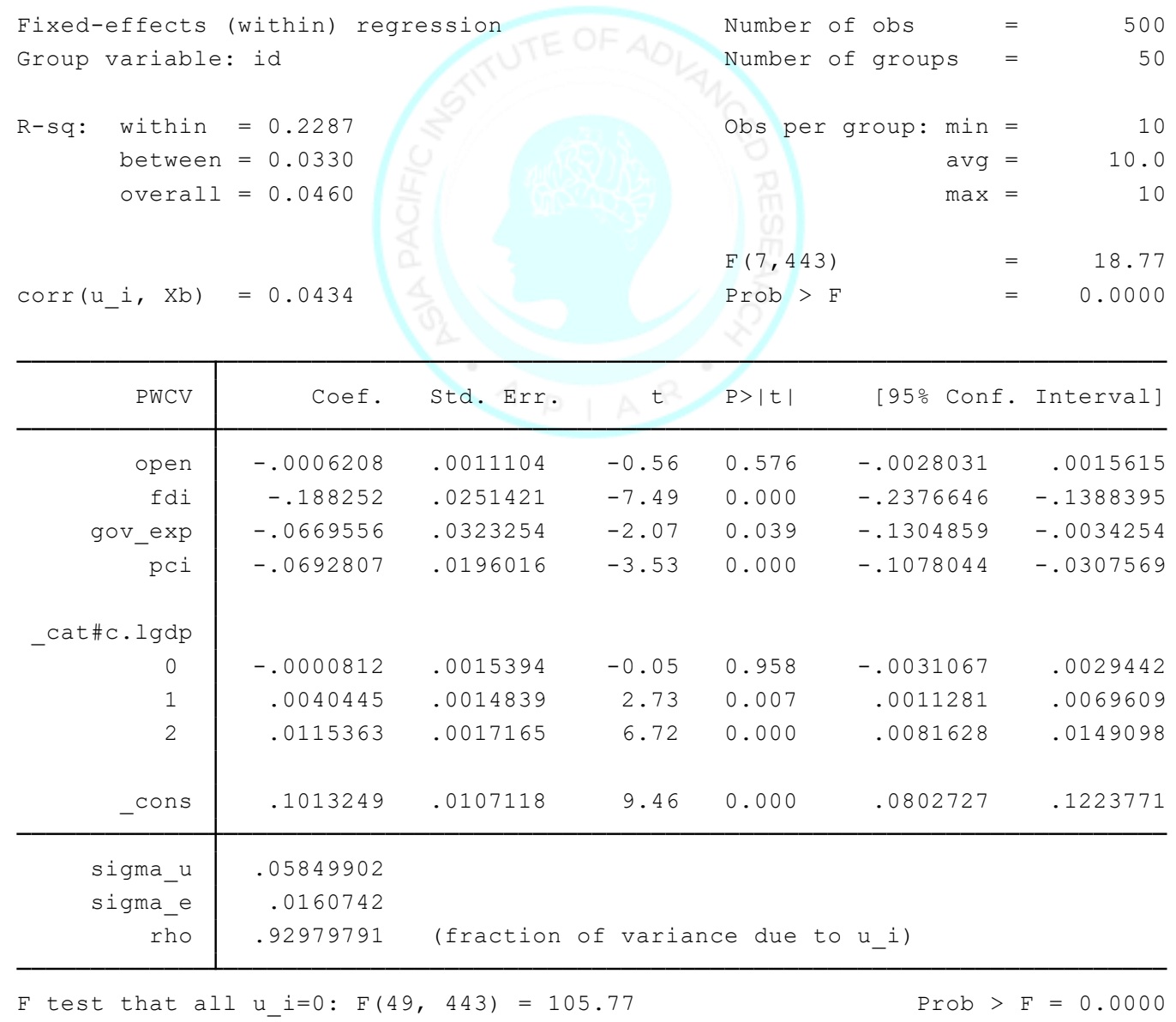

Source: Author's computation in STATA 14 
The F statistic of 105.77 at the $1 \%$ level of significance with the null hypothesis of all $u_{i}=0$ confirms that the fixed effect model is appropriate. The bootstrap p-values of thresholds support the existence of threshold effect at the $10 \%$ level.

The result shows that the increase of FDI flows into Vietnam widens the regional inequality in the country in terms of income. Furthermore, the threshold effect of FDI on income inequality is found. However, this effect is indirect through the influence of FDI on GDP. In particular, the regression slope estimates in Panel Threshold Regression model indicate the threshold effect of FDI in the three regimes:

- When FDI $\leq 4.38 \%$, the negative coefficient implies that each $1 \%$ increase in GDP may reduce regional inequality by $0.0000812 \%$. However, this impact is statistically insignificant with the high p-value of 0.958 .

- When $4.38 \%<$ FDI $\leq 11.96 \%$, we found strong evidence that GDP widens the regional income gap in Vietnam with a p-value of 0.007 . In specific, each $1 \%$ increase in GDP may increase regional inequality by $0.004 \%$.

- When the country continues to attract FDI more than $11.96 \%$ GDP, the indirect impact of FDI via GDP will be even stronger. Each $1 \%$ increase in GDP would increase inequality by $0.011 \%$.

\section{Conclusion}

Using a panel data of cities and provinces in Vietnam in the period of $2006-2015$, this paper examines the relationship between regional income inequality and FDI growth using fixed effect threshold model developed by Hansen (1999). The findings indicate that FDI directly have a negative effect on income equality. Furthermore, the results show that FDI can influence on inequality indirectly through its impact on GDP. We find strong evidence that there are two threshold levels of FDI in the regression relationship. They are $4.38 \%$ and $11.96 \%$ of GDP with asymptotic 95\% confidence interval. These thresholds divide the observations into three regimes, in which the relationship between GDP and inequality has an inverted U shape. This finding is consistent with the previous studies on other countries such as Figini \& Gorg (2011) and Kyriacou\& Roca-Sagales (2012). It implies the tradeoffs of the country when trying to attract FDI. The fact in Vietnam shows that the competition among regional governments for the inward FDI generally deepens the gap between the rich and poor resource regions in the country. In the context that Vietnam has been putting so much efforts to attract FDI, this is a warning of an increase in region income inequality in the near future. 


\section{References}

i. Chintrakarn, Herzer \& Nunnenkamp, 2011. FDI and Income Inequality: Evidence from a panel of US States. Economic Inquiry, 50(3).

ii. Feenstra \& Hanson, 1997. Foreign Investment, Outsourcing and Relative Wages: Evidence from Mexico's maquiladoras. Journal of International Economics , 42(1997), pp. 371-393.

iii. Figini \& Gorg, 1999. Multinational Companies and Wage Inequality in the Host Country: The Case of Ireland. Weltwirtschaftliches Archives, 135(4), pp. 594-612.

iv. Figini \& Gorg, 2011. Does Foreign Direct Investment Affect Wage Inequality? An Empirical Investigation. The World Economy, Blackwell Publishing.

v. Fritzen, 2002. Growth, inequality and the future of poverty reduction in Vietnam. Journal of Asian Economics, 13(5), pp. 635-657.

vi. General Statistics Office of Vietnam, 2016. General Statistics Office of Vietnam. [Online] Available at: https://www.gso.gov.vn/Default en.aspx?tabid=491

vii. Giannetti, 2002. The effects of integration on regional disparities: convergence, divergence or both. European economic Review, Volume 46, pp. 539-567.

viii. Goldin \& Katz, 2008. The race between education and technology. Harvard: Harvard University Press.

ix. Hansen, B., 1997. Sample splitting and threshold estimation, Working paper, Boston: Boston College.

x. Hansen, B., 1999. Threshold effects in non-dynamic panels: estimation, testing, and inference. Journal of Econometrics, Volume 93, pp. 345-368.

xi. Hanson, 2003. What has happened to wages in Mexico since NAFTA?", Implications for Hemispheric Free Trade, Cambridge, MA: National Bureau of Economic Research, NBER Working Paper 9563.

xii. Hanson \& Feenstra, 2003. Global Production Sharing and Rising Inequality: A survey of trade and wages, Cambridge, MA: National Bureau of Economic Research, NBER Working Paper No 8372.

xiii. Herzer \& Nunnenkamp, 2011. FDI and Income Inequality: Evidence from Europe, Kiel Working paper, s.l.: Kiel Institute for the World Economy.

xiv. $\quad$ Kaufmann, D., Kraay, A. \& Mastruzzi, M., 2010. The World Governance Indicators: A summary of Methodology, Data and Analytical Issues. World Bank Policy Research Paper, p. 5430.

xv. Kyriacou, A. \& Roca-Sagalés, O., 2012. The impact of EU structural funds on regional disparitieswithin member states. Environment and Planning C: Government and Policy, Volume 30, pp. 267-281.

xvi. Lessman, C., 2009. Fiscal decentralization and regional disparity: evidence from cross-section and panel data. Environment and Planning A, Volume 41, pp. 2455-2473.

xvii. Lipsey \& Sjöholm, 2004. Foreign Direct Investment, Education and Wages in Indonesian manufacturing. Journal of Development Economics, 73(2004), pp. 415-422.

xviii. $\quad$ McKinnon, R., 1997. Market-preserving fiscal federalism in the American monetary union. In: M. Blejer \& T. Ter-Minassian, eds. Macroeconomic Dimensions of Public Finance: Essays in Honour of Vito Tanzi . London: Routledge, pp. 73-93.

xix. Molini, V. \& Wan, G., 2008. Discovering sources of inequality in transition economies: a case study of Rural Vietnam. Economic Change and Restructuring, Volume 41, pp. 75-96. 
xx. Morrissey, T. V. a., 2002. Foreign Direct Investment, Skills and Wage Inequality in East Asia, Mimeograph: University of Nottingham.

xxi. $\quad$ Oates, 1999. An essay on fiscal decentralization. Journal of Economic Literature, 37(3), pp. 11201149.

xxii. Petrakos, Rodríguez-Pose \& Rovolis, 2004. Growth, integration, and regional disparities in the European Union. Environment and Planning A, Volume 37, pp. 1837-1855.

xxiii. Phan, D. \& Coxhead, I., 2013. Long-run costs of piecemeal reform: wage inequality and returns to education in Vietnam. Journal of Comparative Economics, Elsevier, 41(4), pp. 1106-1122.

xxiv. Prud'homme, 1995. On the dangers of decentralization. World Bank Research Observer, Volume 10, pp. $201-220$.

xxv. Qian \& Weingast, 1997. Federalism as a commitment to preserving market incentives. Journal of Economic Perspectives, Volume 11, pp. 83-92.

xxvi. Vietnam Chamber of Commerce and Industry, 2016. Vietnam Chamber of Commerce and Industry. [Online] Available at: http://e.vcci.com.vn/[Accessed 2016].

xxvii. Vietnam Ministry of Labour, 2016. Vietnam Ministry of Labour - invalids and social affairs. [Online].

xxviii. Wang, 2015. Fixed-effect panel threshold model using Stata. The Stata Journal, 15(1), pp. 121134 .

xxix. Wei; Yao; Liu, 2009. Foreign Direct Investment and Regional Inequality in China. Review of Development Economics, 13(4), pp. 778-791.

xxx. Williamson, 1965. Regional inequality and the process of national development: a description of patterns. Economic Development and Cultural Change, Volume 13, pp. 3-45.

xxxi. World Bank, 2014. Inequality in Vietnam: A special Focus of the Taking Stock Report. [Online] Available at: http://www.worldbank.org/en/news/feature/2014/07/08/key-findings-of-takingstockan-update-on-vietnams-recent-economic-developments-july-2014 